\title{
PROFESSORES SURDOS DIANTE DAS PRÁTICAS PEDAGÓGICAS BILINGUES*
}

Marcio Hollosi

\section{Introdução}

É importante iniciarmos a discussão a partir da educação bilíngue e, mais especificamente, a educação bilíngue para Surdos ${ }^{1}$. Trata-se de uma área que tem mudado, principalmente a partir da década de 1990, por conta dos movimentos políticos dos Surdos pela conquista e garantia dos seus direitos, fundamentados nas pesquisas, especialmente no campo da Educação e da Linguística. A comunidade Surda mobiliza a luta pela igualdade de direitos e por uma pedagogia da diferença Surda, de modo que se reconheça a cultura Surda, a língua de sinais, a experiência visual, o uso das tecnologias, formação do povo Surdo e comunidades, inserção dos intérpretes e tradutores. Assim, alargam-se as discussões sobre uma educação bilíngue de Surdos no Brasil, caracterizada por modos múltiplos de como essa proposta educacional pode ser entendida e vivenciada.

O bilinguismo é um fenômeno complexo e para muitos parece se converter em mito a ideia de que uma pessoa bilíngue possui as duas línguas com a mesma competência linguística e comunicativa. Isso acontece porque nem todos os bilíngues têm as mesmas habilidades nas duas línguas, já que, como nos mostra o quadro 1 , com definições e tipologias trazidas de vários autores, existem diversos tipos de bilinguismo.

Quadro 1: Tipos de Bilinguismo

\begin{tabular}{|l|l|}
\hline Tipos de Bilinguismo & Definição \\
\hline & $\begin{array}{l}\text { Propõe que o indivíduo desenvolva dois sistemas linguísticos } \\
\text { paralelos para usá-los de forma independente e de acordo com a } \\
\text { situação. Para isso, uma palavra tem dois significantes e dois } \\
\text { significados. Esse tipo de bilinguismo é desenvolvido na condição } \\
\text { de que cada pai fale uma única língua para a criança. Desta }\end{array}$ \\
\hline
\end{tabular}

${ }^{*}$ DOI - 10.29388/978-65-86678-60-4-0-f.247-272

${ }^{1}$ De acordo com Sacks (1990), os termos relativos à palavra Surdos serão grafados com "S" maiúsculo pelo entendimento que faz referência a uma entidade linguística e cultural. 


\begin{tabular}{|c|c|}
\hline Coordenado & $\begin{array}{l}\text { forma, a criança constrói dois sistemas que distingue e usa } \\
\text { perfeitamente com habilidade, de maneira que se torna bilíngue } \\
\text { como um bom tradutor. }\end{array}$ \\
\hline Composto & $\begin{array}{l}\text { Propõe a aprendizagem de duas línguas num único contexto, isto } \\
\text { é, os símbolos das duas línguas funcionam como alternativas } \\
\text { intercambiáveis com os mesmos significados (um significado por } \\
\text { dois significantes). O indivíduo não é capaz de detectar diferenças } \\
\text { conceituais marcadas pelas duas línguas, percebendo a vida a } \\
\text { partir de um destes sistemas (condução monolíngue). }\end{array}$ \\
\hline Aditivo & $\begin{array}{l}\text { Ocorre quando o ambiente social em torno da criança pensa que } \\
\text { a aprendizagem de uma segunda língua é um enriquecimento } \\
\text { cultural. São indivíduos bilíngues por escolha, que procuram } \\
\text { classes ou contextos formais nos quais possam aprender uma } \\
\text { língua diferente (geralmente, uma língua que não é comumente } \\
\text { falada nas comunidades em que vivem e trabalham), e eles } \\
\text { continuam a passar a maior parte do tempo em uma sociedade } \\
\text { na qual sua língua materna é de uso primário. }\end{array}$ \\
\hline Subtrativo ou substituto & $\begin{array}{l}\text { Surge em um contexto social em que a aprendizagem de uma } \\
\text { segunda língua pode se tornar um risco de perda de identidade. } \\
\text { Contrariamente ao modelo anterior, se trata de indivíduos } \\
\text { bilíngues por circunstância; pessoas que, devido à sua situação, } \\
\text { acham que precisam aprender outra língua para sobreviver. Na } \\
\text { maioria das vezes, eles estão em um contexto no qual sua língua } \\
\text { étnica não é a língua nacional ou a língua de prestígio ou a língua } \\
\text { da maioria. }\end{array}$ \\
\hline Igual ou equilibrado & $\begin{array}{l}\text { Supõe que a relação de ambas as línguas pode ser de igualdade, } \\
\text { ocupando representações simbólicas de uma determinada } \\
\text { sociedade. }\end{array}$ \\
\hline Desigual ou dominante & $\begin{array}{l}\text { Considera que a relação das línguas é um tipo de subordinação } \\
\text { que é primordial para o outro. }\end{array}$ \\
\hline
\end{tabular}

Fonte: Hollosi, 2019

O quadro nos mostra as definições usadas nas propostas de bilinguismo para ouvintes. Entretanto, é comum que educadores Surdos questionem se esses modelos servem para uma educação bilíngue para Surdos, uma vez que acreditamos que a L1 aqui mencionada seria a Libras, na modalidade visuo-gestual, e a L2 o Português que é uma língua de modalidade oral-auditiva, ou seja, estamos tratando de duas línguas de modalidades diferentes. No entanto, a multimodalidade (ou mesmo a bimodalidade) não é considerada no quadro acima. Será que isso traria alguma diferença ou talvez alguns acréscimos ao quadro? 
Se acharmos que sim, talvez valesse investigar que o bilinguismo na educação de Surdos talvez ocorresse de forma muito mais clara se tivéssemos como L1 a Libras e como L2 a ASL (Língua de Sinais Americana), por exemplo; tendo em vista que é outra língua de sinais, visuo-gestual, e seriam da mesma modalidade. Isso posto, o português escrito também passaria a ser a L1, na modalidade escrita, tendo o inglês escrito (ou outra língua escrita) como L2. Por essa lógica, se reconheceria as duas modalidades em que o Surdo precisa aprender para conseguir atuar nos dois mundos em que habita: duas modalidades ensinadas de formas diferentes, pois são modalidades distintas, sem que a aprendizagem de uma língua em uma determinada modalidade seja necessariamente pressuposto para a aprendizagem de uma língua na outra. Trata-se de um conceito defendido em Hollosi (2019) como um bilinguismo para Surdos, em um modelo educacional bilíngue para Surdos, sendo ambas as línguas empregadas como línguas de mediação pedagógica dos docentes que as ensinam.

\section{A educação bilíngue para Surdos.}

Segundo Botelho (2005), no Brasil a educação bilíngue ainda é pouco divulgada e discutida, mas existem alguns países, como Dinamarca e Suécia, em que os sujeitos Surdos são formados em língua de sinais, leitura e escrita. Na Suécia, desde 1981, foi implementado o bilinguismo e a língua de sinais sueca passou a ser oficialmente a língua de instrução do Surdo. Vale lembrar que, no Brasil, ainda hoje, essa proposta de educação bilíngue está em discussão, a Libras, apesar de reconhecida em lei, não é oficial e, por isso mesmo, não há obrigatoriedade de amplo ensino dessa língua nas escolas.

$\mathrm{Na}$ escola bilíngue sueca foi criado um currículo que determinava a língua de sinais como disciplina de modo a promover a admissão de professores e funcionários surdos no espaço escolar com vias a formar outros profissionais responsáveis pela formação de Surdos em termos de fluência e aprendizagem da língua de sinais.

Ainda sobre a Suécia, em outras esferas da sociedade foram admitidos funcionários Surdos, tanto na iniciativa pública, quanto na iniciativa privada. Foram feitos investimentos para a produção de materiais visuais e escritos, além do oferecimento de cursos de língua de sinais para quem se interessasse. 
No seio familiar, a comunicação entre pais ouvintes e filhos Surdos acontece por meio da língua de sinais, favorecendo o desenvolvimento da lingu(agem) ${ }^{2}$.

Na Suécia, existem três situações que favorecem o modelo bilíngue: a pesquisa sobre a língua de sinais, a participação da Comunidade Surda e a cooperação das organizações de pais de Surdos. A pesquisa sobre a língua de sinais acaba por criar uma identidade e um reconhecimento dos Surdos em relação à língua. Dessa forma, eles passam a utilizá-la em diferentes contextos da sociedade, já que, a partir da Associação Nacional de Surdos da Suécia, começa a haver participação ativa desse público. Isto é, todo tipo de informação, hoje, está disponível para os Surdos em sua primeira língua, sendo usada como meio de comunicação entre Surdos e seus pares, sejam estes também Surdos ou ouvintes.

No Brasil, segundo Souza (2012), a proposta bilíngue "depende da mudança de perspectiva das políticas públicas sobre Surdos e surdez; a prática do bimodalismo como sinônimo de bilinguismo inviabiliza a efetivação dessa proposta". É imprescindível o real conceito prático e efetivo da língua de sinais para que os Surdos possam comunicar de forma independente na sociedade em que convivem atualmente. No entanto, a visão de bimodalidade que persiste na sociedade brasileira mantém a língua de sinais em um cativeiro em relação à língua portuguesa, visto que o Surdo não pode se formar em sua língua, seguir uma vida acadêmica em sua língua e ainda são poucas as oportunidades profissionais em que a Libras é aceita (quase) em posição de igualdade com o português.

Em outros países (não só na Suécia), como nos Estados Unidos por exemplo, segundo Sacks (1990), depois de um certo tempo, os Surdos optaram pela escolarização através ou a partir da língua de sinais para o processo de uma constituição de sua identidade. Podemos citar o que aconteceu na Universidade de Gallaudet (Universidade para Surdos, situada na cidade de Washington nos Estados Unidos) que, entre outros fatores, lutou para ter um reitor Surdo de modo a que a língua de sinais pudesse realmente ser vista como um elemento de identidade do Surdo. O ensino-aprendizagem e a construção de conhecimentos se dão por meio dessa língua. Portanto, o Surdo não precisa transpor tudo o que ele compreende e constrói em sua língua para

\footnotetext{
${ }^{2} \mathrm{~A}$ escrita de lingu(agem) é defendida por Fidalgo (2006) para quem a língua é ação e, como tal, pode ser questionadora e transformadora das realidades, das situações de desigualdade.
} 
a língua oral (o inglês) e vice-versa. Ele não precisa pedir permissão linguística à língua oral para poder produzir conhecimento.

A luta na Gallaudet também se deu por entenderem que o reconhecimento da capacidade do Surdo de gerir uma universidade coloca os membros dessa comunidade em uma posição de autonomia perante a sociedade majoritariamente ouvinte e reconhecidamente excludente em relação ao Surdo e sua capacidade de aprender-ensinar.

No Brasil, essa realidade também vem sendo marcada por lutas apontadas em diferentes pesquisas, desde o final do século passado e o início deste (SKLIAR, 1997, 1999; PERLIN, 1998; PERLIN \& QUADROS, 2003; MIRANDA, 2001), até trabalhos mais recentes que continuam o processo de resistência.

Dessa forma, embora mais lentamente do que em países como a Suécia e os Estados Unidos, no Brasil a educação de Surdos na perspectiva bilíngue tem sido discutida e definida pelos próprios movimentos Surdos, estando a Comunidade Surda na linha de frente dessa luta, em um país que ainda se entende, equivocadamente, como monolíngue. Entretanto, embora no Brasil ainda estejamos lutando por uma educação bilíngue para os Surdos, há, em muitos aspectos, no mundo (e na cultura ouvinte também em nosso país) um movimento pró multiculturalismo ${ }^{3}$, multilinguismo ${ }^{4}$ ou mesmo

\footnotetext{
${ }^{3}$ Em termos bem simples, o multiculturalismo trata da coexistência de várias culturas num mesmo território, país etc. No entanto, é preciso pensar no que seja cultura e na possibilidade real de multiculturalismo - como o fazem vários autores que discutem o termo direta ou tangencialmente (BHABHA, 2006; HALL, 2003, por exemplo). Ao discutir os estudos culturais, Johnson (2006, p. 13) esclarece que é preciso levar em conta três premissas básicas. "A primeira é que os processos culturais estão intimamente vinculados com as relações sociais [...] . A segunda é que cultura envolve poder, contribuindo para produzir assimetrias nas capacidades dos indivíduos e dos grupos sociais para definir e satisfazer suas necessidades. E a terceira [...] é que cultura não é um campo autônomo [...] mas um local de diferenças e lutas sociais." Não podemos esquecer de uma definição como esta para que não se pense que estamos tomando multiculturalismo como natural, linear ou um dado a que se chega sem desafios.

${ }^{4}$ Conhecimento de mais de uma língua, por um mesmo falante. Característica de país ou comunidade em que são faladas mais de duas línguas. No entanto, uma discussão similar à feita na nota 2, sobre multiculturalismo pode ser feita também sobre o multilinguismo. Não podemos achar que essa convivência de duas ou mais línguas é pacífica e há inúmeros exemplos disso. Se fosse pacífica e natural, todos falaríamos, no Brasil, diversas línguas indígenas, as línguas dos povos que para cá se mudaram em diferentes momentos da história e, por que não, libras. Há uma luta por soberania que se estabelece também pela língua. E, portanto, há uma resistência dos falantes das outras línguas para que o povo de um país (o Brasil por exemplo) seja mais multi ou plurilíngue.
} 
plurilinguismo, como afirma o documento do Quadro Comum Europeu (CONSELHO DA EUROPA, 2001).

Diante do que foi discutido, parece-nos que a notícia mais positiva é a que vem dos países nórdicos, tendo a Suécia como referência. Neles, a educação bilíngue não é uma opção; é uma obrigação. Os alunos Surdos são distribuídos em cidades-modelo, que têm recursos suficientes para uma verdadeira cultura bilíngue. A educação se dá com o reconhecimento e a prática da língua de sinais como materna ${ }^{5}$, na qual eles já estão totalmente imersos quando começam a escrever. Além disso, há incentivo em massa para que os pais aprendam a língua de sinais.

$\mathrm{Na}$ realidade brasileira, entretanto, podemos demonstrar resumidamente, o que há de expectativas e realidade para o funcionamento da educação bilíngue para Surdos no seguinte quadro:

Quadro 2 - Expectativas e realidade para o funcionamento da educação bilingue para Surdos

\begin{tabular}{|l|l|}
\hline Expectativa & Realidade \\
\hline Professores fluentes em língua de sinais; & Falta de professores com fluência na língua \\
Entendimento do indivíduo Surdo como & de sinais; \\
capaz de aprender com as qualidades & Baixa expectativa, ainda, dos professores em \\
apropriadas; & semelhança à capacidade dos alunos Surdos; \\
Avaliações registradas na língua de sinais; & Conflitos entre visão médica e antropológica, \\
Produção de artigos na língua de sinais; & embora ter reconhecimento da lei; \\
Formação dos professores Surdos em língua & Avaliações em escolas constituindo em \\
de sinais com enfoco na autêntica & português. \\
preparação para afrontar uma sala bilíngue; & Língua de sinais frequente como mero \\
Materiais bilíngues e recursos indispensáveis & instrumento para aprendizagem mais célere \\
para o trabalho em sala de aula; & da língua oral; \\
Base para as famílias das crianças Surdas e & Escolas ainda não têm materiais e recursos \\
associações; & que favoreçam o ensino aprendizagem de \\
Prática das políticas públicas para tornar o & Libras. \\
projeto duradouro. & $\begin{array}{l}\text { Diversas leis e políticas públicas são } \\
\text { publicadas (parece que a cada mudança de } \\
\text { governo, há uma nova lei ou política pública } \\
\text { para a educação), mas estas não são } \\
\text { praticadas por falta de conhecimento ou de } \\
\text { recursos. }\end{array}$ \\
\hline
\end{tabular}

Fonte: Hollosi, 2019.

${ }^{5} \mathrm{~A}$ discussão sobre a possível distinção entre língua materna e primeira língua não será alvo deste trabalho. 
Como o quadro evidencia, o cenário brasileiro é bipolarizado e passa por um nivelamento linguístico, especialmente pela influência dos meios de comunicação de massa, pelo deslocamento do campo para a cidade e pela ampliação do ensino público, sem, no entanto, haver formação para o professor trabalhar com alunos Surdos. Observa-se, no nosso atual contexto, definido ainda como monolíngue (e talvez mais próximo de um bilinguismo em relação à língua inglesa do que em relação à Libras), um comportamento conservador das camadas mais privilegiadas da sociedade, voltado aos padrões exigidos desde o período colonial - período em que o Surdo era segregado por ser considerado incapaz.

Nas categorias populares, ocorrem modificações linguísticas significativas, decorrentes do contato do português com as línguas indígenas e africanas. Evidentemente, a língua muda com o tempo e essa mudança acompanha os séculos e não é realizada de maneira instantânea. Ela é gradual e não depende apenas do indivíduo, mas, também, da comunidade que o insere, de acordo com os conceitos de Vygotsky. O contato entre línguas, a imposição da língua dominante sobre o dominado e a aprendizagem precária de uma língua são ocorrências de forte impacto para constituir a língua nacional do Brasil. As camadas médias e altas da sociedade tentam impor uma língua única, porém, sabemos que ela é heterogênea e variável, ainda que falemos só do português. O Brasil, portanto, é multilíngue.

Segundo Quadros (1997, p. 27),

[...] não é incentivado o ensino de línguas com qualidade, não é trazido para dentro do espaço escolar a multiplicidade linguística brasileira. Pelo contrário, o ensino da língua portuguesa é quase exclusivo, uma vez que representa a "língua oficial" do país.

E, poderíamos acrescentar, quando Quadros diz: “[...] o ensino da língua portuguesa é quase exclusivo...", que se trata do português padrão, excluindo-se o multilinguismo que existe quando alteramos em conta as influências indígenas (de diferentes etnias) e africanas (de vários países) já citadas, além das influências, historicamente falando, de franceses, holandeses, dos imigrantes italianos, japoneses, de culturas árabes, entre outros e, hoje, das comunidades de refugiados que temos recebido. 
Há pouco reconhecimento desse multilinguismo e, no que diz respeito à língua de sinais, esse reconhecimento é ainda menor. Segundo Sacks (1990, p. 68), antes de 1960, a língua de sinais (nos Estados Unidos):

[...] não era considerada, nem mesmo por quem a empregava, uma verdadeira língua, com gramática própria.' Isso vale para o Brasil, com o agravante de que estamos, ainda hoje, tentando o reconhecimento da maioria da população.

Ofertar apenas o aprendizado da língua oficial para a criança Surda e privá-la da aprendizagem da Língua de Sinais, como sua primeira língua, equivale a negar os seus direitos e impossibilitar o seu desenvolvimento. Retomando Sacks, a respeito dos Surdos e a aprendizagem da língua:

[...] incapazes de ouvir seus pais, correm o risco de ficar seriamente atrasados, quando não permanentemente deficientes, na compressão da língua, a menos que se tomem providências eficazes com toda a presteza. E ser deficiente na linguagem, para um ser humano, é uma das calamidades mais terríveis, porque é apenas por meio da língua que entramos plenamente em nosso estado e cultura humanos, que nos comunicamos livremente com nossos semelhantes, adquirimos e compartilhamos informações (SACKS, 1990, p.19).

Assim, não parece lógico exigir da criança Surda a aprendizagem da língua oral-auditiva pelo fato de não estar exposta a ela por causa da surdez. Aprender a língua de sinais como primeira língua é fundamental para ordenar o pensamento, já que essa relação pensamento-língua(gem) eficaz na realização dos processos cognitivos. Priorizar a língua portuguesa na educação de Surdos impede o desenvolvimento do instrumento linguístico, o qual organiza as experiências apreendidas e as inferências psicológicas. Sabe-se (e isso é corroborado pelos estudos de Quadros, 1997 entre outros autores) que a língua de sinais deve ser considerada a primeira língua do Surdo (L1) e a língua portuguesa, sua segunda língua (L2).

$\mathrm{O}$ acesso à Língua de Sinais - e o encontro Surdo-Surdo - acontecem tardiamente pelo fato de a criança Surda não ser exposta à comunicação visuogestual, devido aos pais serem ouvintes. Tal situação seria enriquecida caso pais e filhos imergissem em ambos os códigos linguísticos; entretanto, "o poder está nas mãos dos que ouvem e falam para dizer à sociedade em geral e 
aos Surdos quais os termos que os descrevem e os diferenciam" (LULKIN, 2010, p. 43).

A proposta bilíngue parece ser apenas utilizada como mecanismo para a língua portuguesa se tornar a responsável pelo acesso ao conhecimento, de modo que a Língua de Sinais passa a ser usada como instrumento. Nos espaços escolares a Língua de Sinais é coadjuvante e o português ocupa o papel principal sempre, caracterizando práticas de exclusão dos Surdos. Não se trata somente de concepções linguísticas, mas, também, de proposições políticas. Por conta disso, muitas escolas não conseguem incluir a Libras como currículo e ser o principal no processo de aprendizagem do aluno Surdo.

Quadros (2003, p. 99) destaca ainda a necessidade de organização do currículo para garantir a promoção de todos os conteúdos escolares na própria língua da criança, como forma de reconhecimento da diferença, porque o processo educacional se consolida pelas interações sociais.

Nesse sentido, vale destacar a participação de professores Surdos no apontamento sobre o que significam as diferenças e como elas precisam ser estimadas no currículo para refleti-las e constitui-las em dispositivo cultural e social, fundamental no processo formador de identidades. De tal modo, conforme Skliar (2000), Perlin e Strobel (2009, p. 33), se a base da cultura não estiver presente no currículo, o caminho se torna árduo para o sujeito percorrer a trajetória de sua nova ordem, oferecida nas manifestações culturais.

A didática Surda contravém porque é diferente de práticas presentes em outras línguas e por ser introduzida e praticada por professores Surdos, até então desacreditados, devido às posições de poder. Reis (2006) traz destaques de que a transgressão/desconstrução ocorre meramente pelo fato de os professores Surdos notarem necessário desconstruir e construir do jeito Surdo a prática didática, ou seja, o jeito de ensinar que mais se aproxima do jeito Surdo de aprender, é o que possibilita desenvolver maneiras próprias em suas interações sociais.

Uma escola bilíngue de fato precisa ensinar, de forma intercedida, por uma ou mais línguas, e não apenas ensinar as línguas. Esta é a diferença em relação à escola de idiomas: o aluno não tem apenas aulas de Libras, inglês, italiano, português, mas tem as disciplinas escolares em Libras, português ou inglês. Dependendo da proposta da escola, será conciso determinar qual será a língua de mediação para o ensino das disciplinas e o ensino de uma segunda 
língua ou, até, se não haverá língua de mediação e o aluno terá que compreender o que está sendo ensinado em cada uma das línguas por meio de outros recursos (desenhos, filmes, objetos etc.). No caso de uma escola bilíngue para Surdos, a segunda língua será a língua portuguesa na modalidade escrita e o tratamento deveria ser o mesmo, ou seja, o aluno deveria aprender português sem muita interferência da Libras, sem a tradução direta, como ocorre em muitos ambientes porque não existe equivalência entre línguas. A tradução direta (ou mesmo a visão bimodal) dá a impressão de que existiria equivalência entre as duas línguas - o que diminui a importância de cada uma das culturas, deixando as línguas como meros códigos.

Vale destacar que uma escola bilíngue de qualidade deve se pôr em evidenciar as diferentes línguas em diferentes níveis, porque assim proporciona aos alunos capacidades indispensáveis para saber usar duas ou mais línguas em diversas circunstâncias sociais, culturais, educacionais, médicas entre outras. Em outras palavras, a escola precisa, basicamente, ensinar ao aluno como atuar no mundo, por meio de universos culturais que se abrem pela via de ambas as línguas em uso.

As escolas, no Brasil, precisam seguir as normas da LDB - Lei de Diretrizes e Bases da Educação, por ordem do MEC e dos conselhos de educação. De acordo com as diretrizes desses órgãos, as escolas devem ter 200 dias letivos, no mínimo, além de seguir documentos de política educacional, como os PCNs - Parâmetros Curriculares Nacionais - e, atualmente, as Bases Comuns. No caso da educação de Surdos, um dos principais problemas é que não existe PCN para Libras e o documento de língua portuguesa é um modelo de ensino de primeira língua para ouvintes. Para agravar esse quadro, embora o artigo 4 ㅇ da Lei 10.436/02 diga que Libras deveria ser parte integrante do PCN, este (lançado no final da década de 1990) não foi revisado para a inclusão da língua brasileira de sinais. A falta de um parâmetro para ensino de Libras resulta em que cada cidade ou mesmo cada escola ensine o que achar mais conveniente, resultando em uma ausência de conteúdo básico comum (como um Núcleo Comum) que possibilite ao aluno sair da escola $A$, na cidade $A$, e mudar se para a escola $B$, na cidade $B$, e, ainda assim, ter garantida a continuidade do que vinha aprendendo.

Isso está embasado legalmente, uma vez que a própria Lei 10.436/02 diz que a Libras não deve substituir a língua portuguesa. Dessa forma, a Diretoria de Ensino pode compreender que o aluno deve aprender o português 
na escola (como parte do núcleo comum) e deverá aprender a Libras paralelamente. No entanto, ao mesmo tempo, a impossibilidade de haver Libras como núcleo comum impede que a escola se torne bilíngue. Ela se mantém uma escola especial e, como tal, não poderá funcionar em dois períodos (período integral) para que ambas as línguas sejam ensinadas (como ocorre em escolas bilíngues de línguas orais).

Há outras implicações relativas a essa compreensão da lei. Por exemplo, a avaliação dos alunos deve ser em português porque essa é a língua do núcleo comum da escola. Nos dados produzidos para esta pesquisa, fica claro que apesar de o professor ensinar em língua de sinais, acaba tendo que cobrar a escrita referente ao que foi ensinado, como demonstra o trecho de prova abaixo:

Quadro 3 - Modelo de avaliação escrita de Educação Física.

Nome:

Série: Data:

Avaliação de Educação Física

1. O que é brincar?

2. O conceito de Lúdico?

3. O que é Jogos, Brinquedos e Brincadeiras?

4. O que é ginástica?

5. O que é Dança?

Fonte: Hollosi (2019)

Como é possível perceber, essa política pública acaba exigindo que o ensino seja uma tradução entre duas línguas - que sabemos ser excludente, uma vez que o aluno, ainda em fase de estruturas das duas línguas, não está formado para ser um tradutor. $O$ que se exige dele está bem acima do que ele teria condição de fazer. Logo, trata-se de uma forma que compreende as línguas apenas como códigos intercambiáveis entre si, além de uma forma de excluir o aluno da escola em médio prazo (ou de fazê-lo perder o interesse pela educação). Nega-se a possibilidade de a Libras ser a língua, código linguístico, que para o Surdo lhe é mais acessível ser a base para a resolução de problemas que apresentam na rotina escolar.

Como se pode ver pelo exposto acima, é preciso haver escolas bilíngues para Surdos de qualidade que sejam de período integral ou semi- 
integral (sendo o ensino parcialmente de e em Libras e parcialmente de e em Português, com mediação inicial da Libras, o que não ocorre no Brasil ou, pelo menos, não ocorre nas escolas brasileiras já visitadas pelo pesquisador).

\section{O Professor Surdo no espaço escolar bilíngue}

Gesser (2012, p. 88) afirma que "os Surdos herdaram um legado que é fruto de ações passadas marcadas por opressão, discriminação, dominação e proibições" e atualmente acontecem movimentos que buscam uma nova relação de mudanças na educação de Surdos. A representação do professor Surdo aparece nesse momento a finalidade de adaptar ao aluno Surdo a identidade por meios dos aspectos sociolinguísticos viventes na semelhança entre os sujeitos, que comunicam a mesma forma de perceber o mundo.

Reis (2015) e Campello (2008) também discutem o bilinguismo e a formação do professor Surdo, no entanto, nem uma das duas autoras discorre sobre o espaço escolar bilíngue. Na realidade, essa especificidade ainda é muito pouco discutida no país. O que há, na maior parte dos textos, é a discussão sobre o espaço bilingue do ponto de vista de línguas orais, como em Lorenzo, Trujillo e Vez (2011), Marcelino (2009), Megale (2005).

A seriedade da imagem do professor devido ao seu papel mediador está no que defende Martins (2010) quando diz que:

[...] O professor surdo é alguém que transforma os alunos surdos e que também é transformado pela L2, porque se o professor surdo contribui para o desenvolvimento e a transformação da criança surda, ele também é o mediador da bagagem cultural e conhecimentos de sua formação que estão presentes na sua segunda língua, por isso [...] também é transformado ou influenciado pelas marcas da língua portuguesa durante a sua formação e história (MARTINS, 2010, p. 67).

Além de contribuir para o desenvolvimento linguístico da criança Surda, o professor Surdo tem um importante papel no seu desenvolvimento psíquico, através da afetividade constituída nessa relação.

Rocha (2017, p. 21) diz que a "principal base para formação do profissional da educação é a docência, com ela se envolve o processo de ensino aprendizagem". Sobre isso, Faria (2011) apresenta que um professor 
Surdo é fundamental para o processo ensino-aprendizagem da Libras, por estar constituído de uma cultura linguística e de uma gramática própria.

Entretanto, as pesquisas sobre a formação do professor Surdo parecem seguir um caminho de formação para o ensino da língua, ou seja, o ensino de Libras. Não parece haver pesquisa sobre a formação do professor Surdo que ensina outras áreas do conhecimento, como se não fosse possível haver professor Surdo que lecionasse matemática, física, química, entre outras. Será que todo o professor Surdo tem que ser professor de Libras?

\section{Metodologia}

No presente trabalho, o foco está em analisar a prática bilíngue dos professores em uma escola para Surdos na perspectiva bilíngue. E se inscreve na Pesquisa Crítica de Colaboração (PCCol), conforme investigações de Magalhães, desde 1990, partilhadas e expandidas em livro organizado por Fidalgo e Shimoura (2007) e por autores como Liberali (2008), Aranha (2009), entre outros.

A colaboração crítica apresenta-se como categoria central nessa metodologia porque pressupõe atuação coletiva, apoio mútuo e definição conjunta de objetivos comuns, com papéis assumidos e definidos por todos os participantes, em contextos determinados, em que se compreendam as contradições, trazidas pelas múltiplas vozes dos sujeitos envolvidos na pesquisa. Nesse sentido, é inevitável que a colaboração crítica gere tensões e conflitos nas relações entre os participantes, pois todos têm interesses divergentes, ainda que compartilhados em determinados momentos, e esses interesses e essa partilha possibilitam a criação de ZPDs, que, por definição, estão em constante transformação (ou desenvolvimento), avançando na ressignificação de sentidos individuais e na construção de novos significados coletivos.

A PCCol centraliza, na linguagem, as ações para a construção das relações humanas nos diferentes contextos. No entanto, não se trata de qualquer linguagem. É importante que os participantes se apropriem de uma linguagem argumentativa. Como afirma Liberali (2008) a linguagem organizada pela argumentação é instrumento-e-resultado que cria espaços de colaboração nos quais os participantes discutem sua prática, confrontam ideias e reconstroem suas ações. 
É importante deixar claro que não se trata, em momento algum, de avaliar o professor, mas verificar como movimentam e trazem os seus saberes para o espaço de discussão (e de aula) de modo a tomar decisões na escola e na sala de aula. Utilizamos entrevistas com os professores Surdos, observação e gravação da aula em vídeo, seguidas de sessões reflexivas, também vídeo gravadas.

Nesse panorama, verificamos se há elaboração de novos sentidos (de acordo com o conceito vygotskyano) para a ação didática em sala de aula, por meio do processo de colaboração entre o pesquisador-participante e três professores-participantes, que lecionam no ensino fundamental e médio do Colégio em que a pesquisa se realizou.

Conforme o exposto, apontada para ser um método de investigação alternativo às pesquisas convencionais, a PCCol propõe aos seus participantes construir coletivamente caminhos para responder aos problemas encontrados em contextos sociais por meio da criação de novos conceitos, fornecendo diretrizes para a modificação das ações (MAGALHÃES, 2011). Uma das atividades formativas da pesquisa crítica de colaboração e, neste trabalho, uma das etapas de produção de dados, é a Sessão Reflexiva. Esta se constitui em uma sessão de discussão entre os participantes, incluindo o pesquisador, a partir da observação da aula (da prática do professor participante), com propósito de problematizar, explicitar, delimitar questões e refletir sobre (no caso da presente pesquisa) a didática utilizada pelos professores Surdos, participantes neste trabalho, para o ensino bilíngue por meio da língua de instrução Libras. Espera-se que, a partir das sessões reflexivas, os professores possam ressignificar (ou até transformar) sua prática.

Na sessão reflexiva, possibilita-se descobrir junto com cada professor como este analisa as suas ações; quais são suas concepções teóricas; quais dimensões têm da sua forma de agir; se suas ações contemplam seus objetivos para que a formação de seus alunos seja alcançada. Neste diálogo, os participantes têm o espaço para discutir crenças e valores pessoais que podem até estar em oposição a aspectos culturais mais amplos da comunidade escolar ou, no caso desta pesquisa, da comunidade Surda. O professor pode se questionar, por meio da sessão reflexiva, se as suas ações permitem que o aluno Surdo, do Ensino Fundamental ou Médio, matriculado em sua sala de aula, está alcançando uma formação de qualidade, embasada nos pressupostos da cultura Surda ou se algumas ações fazem parte das crenças 
pessoais desse professor participante. Por esse caminho, pode-se iniciar um processo de acordo e, se necessário, a reconstrução das práticas, em parceria com o pesquisador participante.

Os participantes desta pesquisa são dois professores Surdos, aqui identificados como P1 e P2, um com formação em Educação Física e outro formado em Pedagogia.

\section{Resultados e Análise de dados: \\ Investigação a prática e a didática (estratégias e avaliação) do professor-participante em um cenário bilíngue.}

No quadro 4, analiso a sessão reflexiva da P2. Observe-se que, na coluna um, incluo algum aspecto do meu objetivo ou das perguntas de pesquisa que será analisado por meio do exposto na coluna dois - que é um resumo que faço do sentido contido no exemplo de fala do participante (que está na coluna três).

Quadro 4 - Dados de sessão reflexiva da aula da P2.

\begin{tabular}{|l|l|l|}
\hline $\begin{array}{l}\text { Conteúdo temático } \\
\text { pidartica do professor } \\
\text { bilíngue }\end{array}$ & $\begin{array}{l}\text { É importante saber escrever } \\
\text { a palavra em português } \\
\text { certo nas aulas de Libras. }\end{array}$ & $\begin{array}{l}\text { Pesq.: Durante a aula de } \\
\text { Libras, você explica os } \\
\text { conteúdos em Libras e } \\
\text { depois escreve na lousa em } \\
\text { Português. Certo? Por quê? }\end{array}$ \\
& $\begin{array}{l}\text { P1: Certo, porque Surdo } \\
\text { precisa aprender escrever } \\
\text { palavra certo no português } \\
\text { sempre, mas é importante a } \\
\text { Libras sim como primeira } \\
\text { língua e o português com } \\
\text { segunda língua, porque aqui } \\
\text { escola bilíngue, se eu não } \\
\text { escrever na lousa, como } \\
\text { surdo irá aprender os } \\
\text { significados? }\end{array}$ \\
\hline
\end{tabular}

Fonte: Hollosi, 2019. 
Como se pode ver, nesse momento, a professora P2, ao mesmo tempo em que parece dizer que a língua portuguesa deve ser aprendida a partir da Libras (ou seja, a Libras é língua de mediação), também diz, no final, que o significado do sinal é aprendido pelo aluno com base no português escrito na lousa. Compreende-se, por um lado, que, para essa professora, por se tratar de uma escola bilíngue, as duas línguas precisam ser ensinadas. No entanto, parece haver uma dificuldade, por parte da professora, para salientar a função da língua portuguesa. Isso fica claro quando ela afirma que escreve na lousa para que o aluno consiga entender o significado do sinal. Ora, se Libras é uma língua constituída de forma totalmente diferente do português, em outra modalidade e com estrutura e léxico próprios, como ela poderia depender do português para que seus sinais fossem compreendidos pelos alunos? Parece nos um traço da formação (dos anos escolares) que os professores tiveram, com o português como língua única a fazer sentido.

Se pensarmos que, como diz Vygotsky (1997), o pensamento é organizado pela lingua(gem), então é importante que o aluno Surdo consiga compreender a sua língua por meio dos recursos que esta oferece - e não por meio da intervenção de outra língua. É importante dizer que a professora não atua como professora de português. Portanto, dizer que a escola é bilíngue e que, nesse momento, as duas línguas precisam aparecer em conjunto durante suas aulas não é o que é prescrito como prática de aula de Libras em geral, no Brasil, por pesquisadores como Vieira (2017), Lacerda (1998) Lourenço (2013) Campos (2017).

No entanto, é preciso esclarecer que a escola pesquisada vive um bilinguismo composto que propõe a aprendizagem de duas línguas num único contexto, isto é, os símbolos das duas línguas funcionam como alternativas intercambiáveis com os mesmos significados (um significado por dois significantes). Nesse caso, o indivíduo tem dificuldade de detectar diferenças conceituais marcadas pelas duas línguas ("aprendidas" ao mesmo tempo), percebendo a vida a partir de um destes sistemas, que é uma condução monolíngue.

Algo similar pode ser observado na aula de educação física, demonstrada no Quadro 5 abaixo: 
Quadro 5 - Dados de observação da aula do Professor P1.

\begin{tabular}{|l|l|l|}
\hline Conteúdo Temático & Sentido & Exemplo \\
\hline Estratégias para a prática & $\begin{array}{l}\text { É importante no 8o. Ano } \\
\text { saber a palavra em } \\
\text { português e não repetir o } \\
\text { sinal. }\end{array}$ & $\begin{array}{l}\text { P1: .prática. Eu agora nesse } \\
\text { ano com vocês do 8o. Ano, } \\
\text { vou inverter o ensino, agora } \\
\text { mais teoria pouca prática. } \\
\text { Vocês obrigados saber } \\
\text { escrever em português, } \\
\text { importante palavra, palavra, } \\
\text { palavra, palavra decorar } \\
\text { (professor escolhe um aluno } \\
\text { e sinaliza um sinal referente } \\
\text { teoria de voleibol e } \\
\text { pergunta para o aluno o } \\
\text { nome do sinal). Esse sinal } \\
\text { que estou sinalizado qual é o } \\
\text { nome? (manchete) }\end{array}$ \\
\hline
\end{tabular}

Fonte: Hollosi, 2019.

As aulas de educação física contemplam a palavra da língua portuguesa e não o sinal da Libras e nem o conceito da palavra. Isso demonstra que o professor está mais preocupado com a escrita do que o conceito ou o sinal. Como mostra Fidalgo (2002), quando usa a metáfora da educação bancária de Paulo Freire, o professor, neste caso, faz depósitos de conteúdos apenas, nas cabeças dos alunos e, como o próprio professor relatou na época de escola, as aulas de educação física não tinham nada escrito, só jogos e hoje ele ensina palavras do esporte para os seus alunos Surdos. Aparentemente, ele teve dificuldade, na escola, de compreender os jogos e suas regras, por não partilhar a língua. Essa situação traumática do seu passado o impede de perceber que, em sua didática, seria mais importante para o aluno Surdo entender o sinal e o conceito trabalhado, em um primeiro momento para, em seguida, entender a palavra - visto que se trata de uma aprendizagem com a proposta de ser bilíngue, sendo a primeira língua do aluno a Libras. 


\section{Entender se as intervenções colaborativas serão adequadas para promover ressignificações nos sujeitos e nas práticas envolvidas frente as ações provocadas pelos procedimentos da pesquisa.}

Quadro 6 - Dados da sessão reflexiva com a Professora P2

\begin{tabular}{|c|c|c|}
\hline Conteúdo temático & Sentido & Exemplo \\
\hline $\begin{array}{l}\text { Didática do professor } \\
\text { participante em um cenário } \\
\text { bilíngue }\end{array}$ & $\begin{array}{l}\text { Percepção do uso da Libras } \\
\text { sem a interferência do } \\
\text { Português. }\end{array}$ & $\begin{array}{l}\text { Pesq.: Qual língua você } \\
\text { utiliza para ensinar na sua } \\
\text { aula? } \\
\text { P3: português. } \\
\text { Pesq.: Ensinar? } \\
\text { P3: (expressão facial de } \\
\text { dúvida)... Ensinar. } \\
\text { Pesq.: Você usa o português } \\
\text { como língua de instrução? } \\
\text { P3: natural. } \\
\text { Pesq.: Mas você não é } \\
\text { professor de Libras? } \\
\text { P3: Sim, mas eu confundi, } \\
\text { desculpa, eu ensino usando a } \\
\text { Libras como L1, tenho } \\
\text { certeza que as aulas irão } \\
\text { melhorar e perceber que eu } \\
\text { não precisarei usar a escrita } \\
\text { do português no ensino de } \\
\text { Libras. }\end{array}$ \\
\hline
\end{tabular}

Fonte: Hollosi, 2019.

Durante a sessão reflexiva, momento em que, juntamente com o pesquisador, e por meio de perguntas de intervenção que promovem a reflexão crítica, como indicado por (MAGALHÃES, 2004), a professora P2 refletiu sobre sua aula e sobre a língua que ela usa para ensinar sua disciplina Libras. "Criamos um espaço para que se distanciasses de suas ações, analisasse 
criticamente suas escolhas e construísse novos sentidos aplicáveis à prática pedagógica" (PINHEIRO, 2018, p. 383). Quando refletia sobre a prática, P2 relatou que considerou a aula bastante produtiva porque os alunos perceberam que, naquele momento, estavam tendo aulas de Libras e não de Português, diferenciando uma língua da outra e isso aumentou a participação mais ativa dos alunos Surdos. Dessa forma, podemos dizer que a P2 iniciou um processo em que caminhou para se transformar em uma pesquisadora da sua própria prática, mudando suas ações e alguns aspectos do ensino de língua na prática. Kemmis (1987) define como reflexão crítica "[...] esse processo em que professores se conscientizam do próprio discurso, entendem as contradições do processo social e, nesse contexto, transformam suas ações". A partir disso, ela demonstrou compreender que o ensino de Libras para Surdos não necessita do uso do Português.

É importante observar o processo reflexivo por meio das perguntas e/ou intervenções feitas pelo pesquisador: qual a língua que você ensina? Você usa português? Mas você não é professora de Libras? Essa construção, que se apoia nas respostas do participante para ir crescendo e envolvendo-o na situação de reflexão é o que permite à professora perceber o que havia feito e perceber que não era bem isso que ela tinha a intenção de fazer demonstrado pela resposta da professora que vem em seguida.

Quadro 7 - Observação da aula da P2, após sessão reflexiva:

P2: Inicia a aula sinalizando sem o uso da escrita do Português na lousa. Nesse momento um dos alunos, levanta a mão e pergunta: Não irá escrever na lousa e depois a gente copia no caderno?

P2: Não, Libras não precisa escrever em português porque a aula é de Libras e não português, entenderam?

O aluno responde com um sim aliviado e diz que agora mais fácil a compreensão dos sinais nas aulas de Libras.

Fonte: Hollosi, 2019.

\section{Considerações}

Os dados deste artigo demonstram que a formação inicial que os professores Surdos receberam é insatisfatória diante dos desafios frente as práticas da educação bilíngue e a preparação recomendada não foi oferecida, 
ou é inacessível, visto que os professores Surdos sequer conhecem as orientações oficiais. Parece que não conhecem a pedagogia ou os meios de ensino propostos, as teorias de aprendizagem, carregando uma marca histórica que os participantes receberam em uma educação precária, fragmentada. Moura (2000, p. 142) esclarece que talvez a política educacional da época não percebesse realmente as necessidades dos Surdos e podemos confirmar que, até hoje, ainda não percebe, quando, apesar de termos a proposta de uma educação bilíngue, a confusão de ensino é tamanha que não sabemos realmente como deve ser a aplicação desse prescrito na prática (ou sua realização).

De acordo com Vygotsky (1997), a dificuldade apresentada pelos Surdos se explica em razão da aprendizagem tardia da língua de sinais e do meio social que é despreparado para recebê-los, e não de uma suposta incapacidade orgânica, gerada em função da perda auditiva, como frequentemente sinaliza a fala da Sociedade. Segundo o autor, a prática pedagógica deve ser orientada de acordo com o potencial que lhe tem para desenvolver, e não pelo que lhe falta.

Em relação ao bilinguismo para Surdos, é possível perceber por este trabalho que o chamado bilinguismo ainda está um pouco nebuloso, ou seja, ainda há muita falta de conhecimento sobre o termo - e mais ainda quando se trata de ensino de Libras e português. Os participantes demonstram não ter certeza sequer se existe bilinguismo - como podemos ver nos dados de P2. Se aceitarmos que bilinguismo existe, somos obrigados a ver que as escolas não sabem como fazê-lo dar certo. Na escola em que a pesquisa ocorreu, por exemplo, todo o material está impresso, mas todas as aulas são em Libras como as discussões de dados mostraram. Então, como o aluno será capaz de ler o que está impresso se ele não está aprendendo português? Bilinguismo é um fenômeno social e para que haja bilinguismo é preciso que as aulas sejam ministradas nas duas línguas - não ao mesmo tempo porque isso seria similar a português sinalizado, mas em aulas subsequentes. Em outras palavras, seria preciso haver uma aula de matemática, por exemplo, em Libras e outra em português, permitindo, assim, que o aluno pudesse construir seu conhecimento matemático nas duas línguas paralelamente. Mas como fazer isso se o aluno ainda não sabe o básico do português e continua, mesmo em séries de Ensino Médio, construindo os conhecimentos básicos mesmo em Libras? Essas são lacunas não respondidas e que podem vir a ser objeto de 
estudos futuros do pesquisador, assim como podem ser objeto de pesquisa de outras pessoas.

Vale sempre ressaltar mais e mais que uma escola bilíngue de fato deve ensinar de forma mediada por uma ou mais línguas e não somente ensinar as línguas, porque essa é a diferença em relação à escola de idiomas, isto é, na escola regular (ou comum) o aluno não tem apenas aulas "de" Libras, inglês, espanhol, português, mas tem as disciplinas escolares "em" Libras, português ou inglês, dependendo da proposta da escola que precisa definir qual será a língua de mediação para o ensino das disciplinas e o ensino de uma segunda língua. No caso de uma escola bilíngue para Surdos, a segunda língua será a língua portuguesa na modalidade escrita, conforme está descrito no Decreto 5626/05. É importante lembrar que uma escola bilíngue de qualidade deve se estabelecer em diferentes níveis porque assim, proporciona aos alunos capacidades necessárias para saber usar duas ou mais línguas em diversas circunstâncias sociais, culturais, educacionais, médicas entre outras.

Durante a pesquisa com os professores Surdos verifiquei alguns problemas, como por exemplo: o professor surdo de outras disciplinas (história, por exemplo) nem sempre sabe português suficiente para ensinar. Por outro lado, o professor de geografia, que é ouvinte, não sabe Libras para ensinar ao Surdo, usando a Libras como língua de apoio se for preciso. E o aluno não sabe português para acompanhar a aula de geografia em português sem o apoio da Libras e nem Libras suficiente para acompanhar a aula de Sociologia em Libras. Vejo esses detalhes como um problema de formação que deve perdurar porque os jovens também estão sendo formados de forma fragmentada, bancária e sem condições de refletir ou opinar sobre a sua formação ou construir conjuntamente os conhecimentos de que necessita para a vida.

\section{Referências}

ARANHA, E. M. G. O Papel do diretor escolar: uma discussão colaborativa. 2009, 189 p. Dissertação (Mestrado - Linguística Aplicada e Estudos da Linguagem) Pontifícia Universidade Católica de São Paulo, São Paulo, 2009.

BHABHA, Homi K. O local da cultura. Belo Horizonte: Humanitas, 2006. 
BOTELHO, Paula. Linguagem e Letramento na educação de surdos: ideologias e Práticas Pedagógicas. Belo Horizonte: Autêntica, 2005.

CAMPELLO, A. R. Pedagogia visual na educação dos surdos-mudos. 2008. 165 p. Tese (Doutorado em Educação) - Universidade Federal de Santa Catarina, Florianópolis, 2008.

CAMPOS, S. R. L. A representação social dos professores de surdos sobre o ensino de Libras e Língua Portuguesa no Ensino Fundamental I. 2017; 281p. Tese (Doutorado em Educação) - Universidade de São Paulo, São Paulo, 2017.

CONSELHO DA EUROPA. Quadro comum europeu de referência para as línguas: aprendizagem, ensino, avaliação. Edição portuguesa. Porto: Edições Asa, 2001. Disponível em:

http://area.dge.mec.pt/gramatica/Quadro_Europeu_total.pdf. Acesso em: 10 ago. 2019.

FARIA, J.G. Formação, Profissionalização e Valorização do professor surdo: reflexões a partir do decreto 5.626/2005. Revista Brasileira de Educação Especial, Marília, v.17, n.1, p. 87-100, 2011.

FIDALGO, S. S. A avaliação de ensino-aprendizagem: ferramenta para a formação de agentes críticos. 2002. 133f. Dissertação (Mestrado em Linguística Aplicada e Estudos da Linguagem) - Pontifícia Universidade Católica de São Paulo-PUC/SP, São Paulo, 2002.

FIDALGO, S. S. ; SHIMOURA, Alzira. Pesquisa Crítica de Colaboração: um percurso na Formação Docente. São Paulo: Ductor, 2007, v. único. p.309.

GESSER, Audrei. O ouvinte e a surdez: sobre ensinar e aprender a Libras São Paulo: Parábola Editorial, 2012.

HALL, S. Da diáspora: identidades e mediações culturais. Belo Horizonte: Humanitas. 2003. 
HOLLOSI, M. Professor surdo: desafios na construção de uma prática bilíngue. 2019. Tese (Doutorado em Ciências: Educação e Saúde na Infância e Adolescência)- Universidade Federal de São Paulo. Programa de PósGraduação em Educação e Saúde na Infância e na Adolescência. Guarulhos, SP, 2019.

JOHNSON, R. O que é, afinal, Estudos Culturais? In JOHNSON, Richard; ESCOTEGUY, Ana Carolina; SCHULMAN, Norma (orgs). $\mathbf{O}$ que é, afinal, estudos culturais. Belo Horizonte: Autêntica. 2006.

KEMMIS, S. Critical reflexion. In: WIDEEN, M. F. ANDREWS, I. Staff development for school improvement. The Falmer Press, 1987. p. 71-90.

LACERDA, C. B. F. Um pouco da história das diferentes abordagens na educação dos surdos. CEDES, Campinas, v.19, n.46, p. 277-292, set.1998.

LIBERALI, F.C. Formação crítica de educadores: questões fundamentais. Taubaté, SP: Cabral Editora e Livraria Universitária, 2008.

LORENZO, F. TRUJILLO, F y VEZ, J. M. Educación bilingüe. Integración de contenidos y segundas lenguas 2011.Madrid: Síntesis, 323 págs.

LOURENÇO, E. A. G. Revista Educação Especial , v. 26, n. 45, p. 161-174, jan./abr. 2013. Santa Maria.

LULKIN, S. Os estudos surdos em Educação: práticas de controle do corpo e a expressão cultural amordaçada. In: SKLIAR, C. A surdez: um olhar sobre as diferenças. Porto Alegre: Mediação, 2010.

MAGALHÃES, M.C.C. Formação Contínua de Professores: Sessão Reflexiva como espaço de negociação entre professores e pesquisador externo. In: FIDALGO, S.S; SHIMOURA, A.S. (Orgs). Pesquisa Crítica Colaborativa: um percurso na formação docente. São Paulo: Ductor, 2007. p. 97-113.

MAGALHÃES, M.C.C. A linguagem na formação de professores como profissionais reflexivos e críticos. In: MAGALHÃES, M. C. (Org.). A formação do 
professor como um profissional crítico: linguagem e reflexão. Campinas, SP: Mercado de Letras, 2004. p. 45-62.

MAGALHÃES, M.C.C. Pesquisa Crítica de Colaboração: escolhas epistemometodológicas na organização e condução de pesquisas de intervenção no contexto escolar. In: MAGALHÃES, M. C. C., FIDALGO, Sueli S.(orgs). Questões de método e de linguagem na formação docente. Campinas: Mercado das Letras, 2011. p 13-40.

MARCELINO, M. Bilinguismo no Brasil: significado e expectativas. Revista Intercâmbio, v. XIX: 1-22 2009. São Paulo: LAEL/PUC-SP. ISSN 1806275x.

MARTINS, M. A. L. Relações professor surdo /aluno surdo em sala de aula: análise das práticas bilíngues e suas problematizações. 2010. 131 f. Dissertação (Mestrado em Educação), Universidade Metodista de Piracicaba (UNIMEP), Piracicaba, SP, 2010.

MEGALE, A. H. Bilinguismo e educação bilíngue - discutindo conceitos. Revista virtual de Estudos da Linguagem - reVEL. Ano 3, n.5, 2005.

MIRANDA, S. De. Do fascínio do jogo à alegria do aprender. Campinas, SP: Papiros, 2001.

MOURA, M. C. de. O surdo - caminhos para uma nova identidade. São Paulo: Revinter/Fapesp, 2000.

PERLIN, G., STROBEL, K. Teorias da Educação e Estudos Surdos. Florianópolis: UFSC, 2009.

PERLIN, G. T. T. Identidades Surdas. In: SKLIAR, C. (org). A surdez: um olhar sobre as diferenças. 2. ed. Porto Alegre: Mediação, 1998. p.51-73.

PINHEIRO, L. M. Adaptações curriculares na "inclusão" escolar de alunos surdos: intervenções colaborativas. 2018. 430 f. Tese (Doutorado em Educação e Saúde na Infância e na Adolescência) - Universidade Federal de São Paulo - UNIFESP/Guarulhos, SP, 2018. 
QUADROS, R. M., Educação De Surdos: A Aquisição Da Linguagem. Porto Alegre: Artmed, 1997.

QUADROS, R. M., PERLIN, G. O ouvinte o outro do outro surdo. In: II SEMINÁRIO INTERNACIONAL EDUCAÇÃO INTERCULTURAL, GÊNERO E MOVIMENTOS SOCIAIS, 2003, Florianópolis. Anais... Florianópolis: Fapeu-002, 2003. v.1. p.617 - of 4.

REIS, F. Professor Surdo: a política e a poética da transgressão pedagógica. 2006. Dissertação (Mestrado em Educação) - Universidade Federal de Santa Catarina, Florianópolis, 2006.

REIS, Flaviane. A docência na educação superior: narrativas das diferenças políticas de sujeitos surdos. 2015. 278 f. Tese (Doutorado em Educação), Universidade Federal de Uberlândia, Uberlândia, 2015.

ROCHA, D. S. Educadores Surdos: reflexões sobre a formação a prática docente. 2017. Dissertação (Mestrado), UNICAMP, Campinas, 2017.

SACKS, O. Vendo vozes: uma jornada pelo mundo dos surdos. Rio de Janeiro: Imago, 1990.

SKLIAR, C. (org). Atualidade da educação bilíngue para surdos. v. 1 e 2, Porto Alegre: Mediação, 1999.

SKLIAR, C. Uma análise preliminar das variáveis que intervêm no projeto de educação bilíngue para os surdos. In: Revista Espaço, Rio de Janeiro: EsV. IV, n. 6, p. 49-57, 1997.

SOUZA, A. C. S. Educação bilíngue para surdos: perspectivas e construções. In: V SEMINÁRIO NACIONAL DE EDUCAÇÃO ESPECIAL E IV ENCONTRO DE PESQUISADORES EM EDUCAÇÃO ESPECIAL E INCLUSÃO ESCOLAR. CEPAE / UFU, 2012, Uberlândia, Anais..., Uberlândia, UFU, 2012. 
VIEIRA, C. R. Educação bilíngue para surdos: reflexões a partir de uma experiência pedagógica. 2017, 236 f. Tese (Doutorado em Educação), Universidade de São Paulo, São Paulo, 2017.

VYGOTSKY, L.S. Obras Escogidas V - Fundamentos de Defectología.

Traducción: Julio Guilhermo Blank. Ed Visor (Coletânea de artigos publicados originalmente em russo entre os anos de 1924 a 1934). Madrid, 1997. 